\title{
ФОРМИРОВАНИЕ ПРОФЕССИОНАЛЬНОЙ ОДАРЕННОСТИ И ЕЕ ДЕТЕРМИНАЦИЯ МОТИВАЦИЕЙ УСПЕХА И РАЗЛИЧНОЙ СТЕПЕНЬЮ СВОБОДЫ В ДЕЯТЕЛЬНОСТИ
}

\section{Т.Н. СОБОЛЕВА ${ }^{\mathrm{a}}$}

${ }^{a}$ Дальневосточный государственный университет путей сообщения, 680021, Россия, Хабаровск, ул. Серышева, д. 47

\begin{abstract}
Резюме
Статья посвящена малоизученной проблеме формирования одаренности в условиях различной степени свободы в деятельности; определяется, какое влияние на это формирование оказывает низкая или высокая мотивация успеха, присущая субъекту. Выявлены и описаны три степени свободы в деятельности: низкая степень свободы обусловлена нормативным способом действия; средняя степень свободы обусловлена скомбинированным способом действия, из имеющихся в опыте субъекта и нормативных инструкциях; высокая степень свободы обусловлена созданием нового способа действия. Основная задача исследования состоит в раскрытии того, как условия различной степени свободы в деятельности преломляются во внутренних условиях, в качестве которых выступают низкая и высокая мотивация успеха и различные структуры одаренности. Исследование проводилось на выборке из 54 квалифицированных машинистов железнодорожного транспорта с использованием специализированного тренажера, позволяющего имитировать три степени свободы в деятельности. Психологический анализ деятельности позволил выявить семь способностей, обеспечивающих реализацию деятельности. На основе эмпирических данных показано, что низкая, средняя и высокая степень свободы в деятельности проявляются в различной мере продуктивности деятельности. Низкая и высокая мотивация успеха субъекта в условиях свободы выбора в деятельности не оказывает существенного влияния на продуктивность деятельности. В зависимости от низкой и высокой мотивации успеха формируются различные по составу и мере интеграции структуры одаренности в условиях различной степени свободы в деятельности. С одной стороны, низкая и высокая мотивации успеха выступают в качестве внутренних детерминант, с другой стороны, низкая, средняя и высокая степень свободы в деятельности выступают в качестве внешних детерминант формирования различных структур одаренности.
\end{abstract}

Ключевые слова: свобода в профессиональной деятельности, нормативный способ действия, мотивация успеха, структура одаренности.

\section{Постановка проблемы}

Проблема формирования профессиональной одаренности в детерминации мотивацией успеха под влиянием различной степени свободы в деятельности представляется сложной и малоизученной. Сложность состоит, во-первых, в неоднозначном понимании одаренности и ее состава разными авторами, 
во-вторых, одаренность мало изучена в аспекте профессиональной деятельности, в-третьих, не изучены проявления свободы в профессиональной деятельности.

Зарубежные психологи переводят одаренность в сферу интеллекта, общих и специальных способностей, творческой активности и проблем личности в целом. Такое понимание одаренности привело к развитию преимущественно многофакторных концепций в русле психометрического, измерительного подхода. Однако понимания сущности одаренности не предлагается, в ее исследовании обнаруживается отрыв от деятельности. Внедеятельностный подход к проблеме одаренности приводит к узости теоретических и методологических оснований ее изучения, а также упрощает получение результатов и их интерпретацию.

Преимущество отечественной психологии состоит в исследовании одаренности с позиции деятельностного подхода, в аспекте которого возникло представление о формировании и развитии одаренности в деятельности.

Мультипликативная модель одаренности Д.В. Ушакова (2011), экопсихологическая модель одаренности В.И. Панова (2005), модель художественной одаренности А.А. Мелик-Пашаева (1981), модель проблемного обучения и одаренности А.М. Матюшкина (2003), динамическая модель одаренности Ю.Д. Бабаевой (1997) и др. составляют основу современной отечественной теории одаренности. Ученые стремятся выявить компонентный состав одаренности через сложную систему взаимосвязей интеллекта, способностей, мотивации, личностного смысла с окружающей и образовательной средой, деятельностью и жизненным путем личности.

Проблема системности одаренности решается в «Рабочей концепции одаренности» (авторы: Ю.Д. Бабаева, Д.Б. Богоявленская, А.В. Брушлинский, В.Н. Дружинин, И.И. Ильясов, И.В. Калиш, Н.С. Лейтес, А.М. Матюшкин, А.А. Мелик-Пашаев, В.И. Панов, Д.В. Ушаков, М.А. Холодная, В.Д. Шадриков, Н.Б. Шумакова, В.С. Юркевич). Научный коллектив рассматривает одаренность как системное свойство, которое развивается в течение жизни, является качеством психики. Одаренность определяет возможность достижения человеком более высоких, незаурядных результатов в одном или нескольких видах деятельности по сравнению с другими людьми. Классификация одаренности по критерию «вид деятельности и обеспечивающие ее сферы психики» является перспективной в направлении решения проблемы соотношения одаренности и отдельных способностей, понимания творческой одаренности как особого вида (Богоявленская, Шадриков, 1998).

Обозначенная проблема соотношения одаренности и отдельных способностей является ключевой для понимания сущности одаренности.

К настоящему времени в исследованиях проблемы одаренности не сложилось единого понимания ее структуры, определения ее сущности.

Б.М. Теплов первым обозначил понимание одаренности как качественное сочетание способностей в отношении конкретного вида деятельности (Теплов, 1985). 
В.Д. Шадриков в теории способностей и деятельности предлагает понимание одаренности как системного взаимодействия способностей, направленного на получение желательного результата, выступающего как качественное новообразование субъекта деятельности, имеющего индивидуальную меру выраженности и развивающегося в деятельности и в жизнедеятельности (Шадриков, 2019, с. 211).

Понимание одаренности заключено в определении сущности способностей. Если рассматривать понятие одаренности в отрыве от способностей, то теория и практика упускают из вида источник происхождения и развития одаренности, что делает затруднительным ее качественный анализ.

Понятие «способности» используется достаточно широко и наполняется различным, специфичным содержанием. Однако до сих пор нет его общепринятого определения.

В отечественной психологии к проблеме определения понятия способностей обращался Б.М. Теплов. Он выделил четыре признака, входящие в понятие «способности»: 1) это свойство, которое имеет отношение к успешности выполнения какой-либо деятельности или многих деятельностей; 2) это индивидуально-психологические особенности, отличающие одного человека от другого; 3) понятие «способность» не сводится к тем знаниям, навыкам или умениям, которые уже выработаны у данного человека; 4) способности по существу дела не могут быть врожденными (Теплов, 1985, с. 20). Вместе с этим он ставил задачу выяснения приблизительной формы и содержания понятия способностей (Там же, с. 15).

Развитие психофизиологического подхода к проблеме способностей в работах Э.А. Голубевой, Е.П. Ильина, К.К. Платонова и др. способствовало укреплению позиции, в соответствии с которой под способностями можно понимать познавательные процессы, такие как память, мышление, интеллект, а также общие свойства нервной системы, но авторы не определяют, каким образом осуществляется переход от памяти, мышления к способности. Вместе с этим сформировалось устойчивое представление о развитии способностей в личностно-деятельностной детерминации, которое получило свое дальнейшее развитие (Голубева, 2005; Ильин, 2004; Платонов, 1972; Богоявленская, 2009).

Д.Б. Богоявленская считает интеллектуальную активность единицей анализа творчества в деятельности. Основная идея развития творческих способностей заключается в формировании способности к саморазвитию деятельности как свойства целостной личности, отражающего взаимодействие когнитивной и аффективной сфер (Богоявленская, 2009).

В.Н. Дружинин, М.А. Холодная, А.В. Карпов экспериментально доказывают, что к общим способностям можно отнести интеллект, обучаемость, креативность, познавательные стили и рефлексию (Дружинин, 2008; Карпов, 2004; Холодная, 2002).

Благодаря работам В.А. Толочка, В.И. Панова, А.Н. Воронина формируется представление о профессиональных способностях как сложных системных образованиях, опосредованных не только деятельностью и личностной 
организацией, но и явлениями, характерными для общества (Воронин, 2011; Панов, 2011; Толочек, 2011).

Таким образом, накоплен большой материал экспериментальных исследований способностей, однако проблема сущности этого явления не решена. Проблема сущности способностей связана с проблемой сущности одаренности.

В.Д. Шадриков впервые раскрывает понятие способностей и обращается к психической функции. Способности рассматриваются как свойства функциональных систем, реализующих познавательные и психомоторные функции, имеющие индивидуальную меру выраженности и проявляющиеся в успешности и качественном своеобразии освоения и реализации деятельности (Шадриков, 2019, с. 102).

Е.П. Ильин разделяет точку зрения о том, что способности следует рассматривать как свойства функциональных систем, реализующих отдельные психические функции. Он подчеркивает, что различия в степени проявления способностей составляют качественную характеристику у разных людей (Ильин, 2004).

Понимание способностей как свойств функциональных систем, реализующих познавательные и психомоторные функции, наполняет конкретным содержанием понимание одаренности как системного взаимодействия способностей, направленного на получение желательного результата, выступающего как качественное новообразование субъекта деятельности.

Рассматривая одаренность как качественное взаимодействие способностей, мы развиваем положение Б.М. Теплова и решаем проблему многокомпонентности одаренности, усматривая в ее структуре только способности. А такие образования, как мотивация, цели, личностные смыслы, личностные свойства, могут рассматриваться в качестве иных внутренних детерминант, оказывающих влияние на формирование и развитие одаренности. В качестве внешних детерминант могут выступать условия образовательной среды, требования деятельности и т.п.

Правомерно предположить, что плодотворное исследование проблемы одаренности возможно в аспекте понимания способностей и одаренности В.Д. Шадриковым, и мы будем придерживаться данного подхода в исследовании профессиональной одаренности.

Настоящее исследование посвящено проблеме профессиональной одаренности, т.е. системного взаимодействия способностей в целях конкретной деятельности, выступающего как системное качество субъекта деятельности, категория деятельности уточняется до конкретного вида профессиональной деятельности. Одаренность субъекта деятельности и есть профессиональная одаренность.

Изучение одаренности в профессиональной деятельности еще более сложно, если ее формирование исследуется под влиянием объективных условий и требований, заключающих в своей основе нормативный способ действия и нормативный результат. А проявление одаренности, как правило, связывают с достижением субъектом выдающихся, творческих результатов. И здесь возникает 
вопрос о правомерности использования понятия одаренности в отношении нормативной деятельности.

Однако большинство отечественных психологов современности признают, что одаренность развивается и формируется в деятельности, она не существует до деятельности. В связи с этим приобретает значение понимание свободы в профессиональной деятельности, а исследование формирования одаренности переводится в ее аспект.

В отечественной психологии деятельностный подход и теория субъекта деятельности глубоко и полно раскрывают проблему свободы выбора субъекта в деятельности.

С.Л. Рубинштейн, создавая теорию психологии субъекта деятельности, сформулировал положение о том, что все внешние воздействия преломляются внутренними условиями, таким образом, на первый план выступают внутренние условия как детерминанты психики, поведения и деятельности (Рубинштейн, 1973). Именно положение С.Л. Рубинштейна о приоритетности субъекта явилось фундаментальным в развитии теории свободы человека при осуществлении деятельности.

Большинством отечественных психологов современности свобода выбора понимается как личная инициатива субъекта, как возможность действовать по-своему, на свой страх и риск в условиях неопределенности и противоречий. Свобода выбора - это возможность самосовершенствоваться, находить новые способы решения противоречия между личностью и требованиями деятельности.

В качестве внутренних детерминант свободного выбора субъектом выделяют мотивы, цели, которые направляют и побуждают субъекта деятельности, а также способности, одаренность субъекта, обеспечивающие достижение результата. В качестве объективных детерминант выделяют требования конкретной профессиональной деятельности.

Свобода выбора выступает как взаимодействие внутренних и внешних детерминант, при котором субъект качественно изменяется сам и изменяется его деятельность, приобретая индивидуальное, творческое своеобразие.

Однако отметим, что психология субъекта деятельности на современном этапе не стала узловой в психологической науке. Методологическое положение С.Л. Рубинштейна о том, что все внешние воздействия преломляются во внутренних условиях, является основным в понимании свободы профессиональной деятельности, имеется ограниченный эмпирический материал, подтверждающий его.

Ярославской психологической школой деятельность изучается с позиции внутренних условий, но нет работ, показывающих, как будут изменяться внутренние условия субъекта, каким образом будут проявляться, структурироваться под влиянием конкретных требований деятельности.

Учитывая позицию В.Д. Шадрикова, опираясь на словарные толкования свободы, а также на теоретические представления о свободе в деятельности С.Л. Рубинштейна, мы придерживаемся следующего определения: свобода в профессиональной деятельности - это способность к определенному поведению 
(действиям), которая, с одной стороны, определяется целями и мотивами субъекта деятельности, а с другой - объективными требованиями и условиями деятельности (Рубинштейн, 1973; Шадриков, 2019).

Под способностью субъекта действовать понимаются различные внутренние условия, в качестве которых могут выступать мотивация и одаренность человека. Формирование одаренности можно исследовать как динамичное объединение способностей в зависимости от мотивации субъекта в условиях свободы выбора в деятельности, обусловленной требованиями. Способности выступают в качестве механизма реализации деятельности. Способности вовлекаются в деятельность и системно взаимодействуют в соответствии с требованиями деятельности, таким образом формируется системное новообразование - одаренность (Шадриков, 2013, с. 109).

Однако возникает вопрос: каким образом может проявляться различная степень свободы в профессиональной деятельности?

Здесь вскрывается важный аспект: деятельность имеет ту или иную степень неопределенности объективных условий и требований. В основе объективной неопределенности лежат нормативные требования. Характер нормативных требований может усложняться в зависимости от конкретных объективных и субъективных факторов, оказывающих непосредственное влияние на деятельность. Изменение характера неопределенности существенно влияет на свободу выбора способа действия.

Степень свободы в профессиональной деятельности заключается в нормативном способе деятельности, который может реализовываться субъектом в его строгой нормативности, либо способ действия комбинируется из имеющихся в опыте и инструкциях, либо осуществляется кардинальное переструктурирование и создается новый способ действия (Абульханова, 1999; Карпов, 2004; Шадриков, 2013).

Три способа действия составляют базовое основание степени свободы в профессиональной деятельности: низкую, среднюю и высокую.

Выбор субъектом одного из трех способов деятельности, а следовательно, степени свободы в деятельности детерминируется, с одной стороны, мотивацией и структурой одаренности, с другой стороны, конкретными требованиями и условиями деятельности.

Мера активности и ответственности субъекта в условиях низкой, средней и высокой степени свободы является различной и напрямую определяется выбором способа действия. Ведущим фактором, определяющим выбор субъектом способа действия, возможно, будет уровень его квалификации.

Учитывая сказанное, мы будем придерживаться следующего определения степени свободь в профессиональной деятельности: это возможность субъекта реализовать инициативные действия в аспекте репродуктивной или продуктивной активности, направленной на выбор такого способа действия, который представляет для него наибольший личностный смысл под влиянием конкретных условий деятельности. Выбор способа деятельности субъектом осуществляется с ориентацией на основные параметры продуктивности деятельности, такие как производительность, надежность и качество. 
Чем выше неопределенность условий и требований деятельности, тем выше степень объективной, внешней свободы и тем большей свободой выбора обладает субъект и реализует ее в принятии решений и действиях.

Согласно различной степени свободы в деятельности, обусловленной способом действия, изучение одаренности применимо как в отношении нормативного, так и необычного, творческого результата деятельности. Данный подход расширяет границы в применении понятия одаренности и ее исследованиях в отношении любой деятельности.

Одаренность является механизмом и внутренним условием реализации низкой, средней и высокой степени свободы в профессиональной деятельности. Назначение одаренности в структуре деятельности состоит в обеспечении субъекта необходимой информацией для достижения цели, которая формируется на основе актуальной потребности.

Формирование системы одаренности происходит как процесс взаимодействия входящих в нее познавательных и психомоторных способностей и установления связей между ними в соответствии с низкой, средней или высокой степенью свободы в деятельности, обусловленной требованиями. Результатом системного взаимодействия способностей выступает новое системное свойство одаренности.

В исследовании необходимо учитывать внутренние детерминанты, которые оказывают влияние на формирование одаренности в условиях различной степени свободы. Мотивация является тем внутренним условием, которое в индивидуальной мере и типе направленности способствует выбору способа действия в условиях различной степени свободы. В свою очередь, мотивация приводит к изменению способа действия, за которым стоит работа конкретной структуры одаренности в условиях различной степени свободы в деятельности.

Исходя из вышеизложенного, можно предположить, что свобода в профессиональной деятельности детерминирована объективными требованиями деятельности, которые реализуются через различные внутренние условия, в качестве которых может выступать одаренность как системное взаимодействие способностей, а также мотивация субъекта деятельности. Реализация субъектом различной степени свободы в деятельности приводит к изменению целостной системы одаренности, что может проявиться в индивидуальной мере продуктивности деятельности.

\section{Организация исследования и методы}

В экспериментальном исследовании приняли участие 54 квалифицированных машиниста железнодорожного транспорта, которые были разделены на три группы по 18 человек: первую группу составили машинисты, реализующие поездку на тренажере в условиях низкой степени свободы в деятельности; вторую группу - машинисты, осуществляющие ту же деятельность в условиях средней степени свободы; третью группу - машинисты, осуществляющие ту же деятельность в условиях высокой степени свободы. Далее 
участники каждой из трех групп были разделены на основании низкой и высокой мотивации успеха.

Сопоставление качественных характеристик трех групп производилось по следующим критериям: возраст, образование, стаж в должности машиниста, класс машиниста, наставничество в течение года, экспертность в течение года, участие в выявлении проектно-конструкторских недостатков при эксплуатации новой техники в течение пяти лет, участие в проектно-конструкторских разработках новой техники в течение пяти лет. Три группы достаточно однородны, являются репрезентативными, что позволяет экстраполировать полученные выводы на генеральную совокупность машинистов железнодорожного транспорта в РФ.

Исследование было проведено в три этапа.

На первом этапе был осуществлен психологический анализ деятельности машиниста, в результате которого выявлен состав профессиональной одаренности, включающий семь наименований способностей, а также была определена мотивация успеха как детерминанта формирования профессиональной одаренности. В таблице 1 представлены перечень способностей, мотивация успеха и методики их диагностики.

На втором этапе осуществлялась диагностика продуктивности под влиянием низкой, средней и высокой степени свободы в деятельности на компьютерных тренажерных комплексах «Торвест-Видео» в моделях: «ВЛС-80», «Ярмак» (разработаны и изготовленные в ЗАО «Научно-производственный центре “СПЕКТР” водилось индивидуально.

Согласно выявленным трем способам действия в условиях низкой, средней и высокой степени свободы, были разработаны и задавались конкретные технические параметры на компьютерных тренажерных комплексах, представленные в таблице 2.

На третьем этапе осуществлялась диагностика структуры одаренности, мотивации успеха (см. описание первого этапа). Индивидуальное обследование квалифицированных машинистов включало 8 методик и проводилось сразу после выполнения задания на тренажере.

\section{Результаты}

Математическая обработка данных проводилась с использованием коэффициента ранговой корреляции Спирмена, поскольку подавляющее большинство данных, полученных в экспериментальном исследовании, нормально не распределено. Различия между тремя независимыми выборками в мере продуктивности деятельности на тренажере определялись с помощью непараметрического критерия Крускала-Уоллеса. При обработке данных использовался пакет статистических программ - SPSS Statistica версия 17.0.

Наряду с этим использовались оригинальные разработки В.Д. Шадрикова, предложенные для оценки меры когерентности системы одаренности, а также 
Состав профессиональной одаренности и методики ее оценки

\begin{tabular}{|c|c|}
\hline $\begin{array}{c}\text { Состав } \\
\text { профессиональной } \\
\text { одаренности }\end{array}$ & Методики диагностики и субъективные опросники \\
\hline $\begin{array}{l}\text { 1. Общие способности } \\
\text { координации } \\
\text { движений тела }\end{array}$ & $\begin{array}{l}\text { Компьютерный стабилографический метод с биологически } \\
\text { обратной связью «Стабилан-01» (ЗАО «ОКБ “Ритм”», г. Таган- } \\
\text { рог): тест со ступенчатым отклонением в одном направлении с } \\
\text { удержанием позы (разработчик - С.С. Слива и др., 2001) }\end{array}$ \\
\hline $\begin{array}{l}\text { 2. Специальные } \\
\text { способности } \\
\text { координации } \\
\text { движений тела }\end{array}$ & $\begin{array}{l}\text { Компьютерный стабилографический метод с биологически } \\
\text { обратной связью «Стабилан-01» (ЗАО «ОКБ “Ритм”», } \\
\text { г. Таганрог): тест на оценку запаса устойчивости человека при } \\
\text { отклонении вперед-назад, вправо-влево (разработчик - } \\
\text { С.С. Слива и др., 2001) }\end{array}$ \\
\hline $\begin{array}{l}\text { 3. Способности } \\
\text { сенсомоторной } \\
\text { реакции рук и глаз }\end{array}$ & $\begin{array}{l}\text { Аппаратурная методика оценки времени сложной двигательной } \\
\text { реакции рук и глаз (авторское право принадлежит компании } \\
\text { ОАО «РЖД», ДВГУПС, 2004) }\end{array}$ \\
\hline $\begin{array}{l}\text { 4. Способности } \\
\text { переключения } \\
\text { внимания }\end{array}$ & $\begin{array}{l}\text { Аппаратурная методика определения скорости переключения } \\
\text { внимания на красно-черных таблицах Шульте-Патонова } \\
\text { (авторское право принадлежит ОАО РЖД, ДВГУПС, 2004) }\end{array}$ \\
\hline $\begin{array}{l}\text { 5. Способности } \\
\text { устойчивости } \\
\text { внимания }\end{array}$ & $\begin{array}{l}\text { Аппаратурная методика определения устойчивости внимания } \\
\text { (авторское право принадлежит ОАО РЖД, ДВГУПС, 2004) }\end{array}$ \\
\hline $\begin{array}{l}\text { 6. Способности мыш- } \\
\text { ления на уровне тех- } \\
\text { нического понимания }\end{array}$ & $\begin{array}{l}\text { Тест «Механика» (разработан Дж. Фланаганом и адаптирован } \\
\text { В.А. Чикером, 2003) }\end{array}$ \\
\hline $\begin{array}{l}\text { 7. Способности } \\
\text { мышления на уровне } \\
\text { реконструкции } \\
\text { технического образа }\end{array}$ & $\begin{array}{l}\text { Тест «Сборка» (разработан Дж. Фланаганом и адаптирован } \\
\text { В.А. Чикером, 2003) }\end{array}$ \\
\hline \multicolumn{2}{|c|}{ Детерминанта формирования профессиональной одаренности } \\
\hline $\begin{array}{l}\text { Низкая и высокая } \\
\text { мотивация успеха }\end{array}$ & $\begin{array}{l}\text { Тест для оценки мотивационной направленности личности (раз- } \\
\text { работан Дж. Кулем (1985) в модификации А.М. Боковикова, } \\
\text { 1999) }\end{array}$ \\
\hline
\end{tabular}

характера структурной организации системы в рамках структурно-функционального подхода.

Методика расчета меры когерентности системы одаренности, согласно процедуре, состоит в следующем. За каждую корреляционную взаимосвязь начисляются баллы по следующему принципу: для $p \leqslant 0.001=4$ балла, для 
Технические характеристики низкой, средней и высокой степени свободы в деятельности на компьютерных тренажерных комплексах

\begin{tabular}{|c|c|c|c|}
\hline Критерии & $\begin{array}{c}\text { Низкая степень } \\
\text { свободы в } \\
\text { деятельности }\end{array}$ & $\begin{array}{c}\text { Средняя степень } \\
\text { свободы в } \\
\text { деятельности }\end{array}$ & $\begin{array}{c}\text { Высокая степень } \\
\text { свободы в деятельности }\end{array}$ \\
\hline $\begin{array}{l}\text { 1. Профиль пути } \\
24 \text { км: спуски и } \\
\text { подъемы, кривые }\end{array}$ & $\begin{array}{l}\text { - от } 0.0 \text { до 4\%о; } \\
\text { - нет кривых }\end{array}$ & $\begin{array}{l}\text { - от } 0.0 \text { до } 7 \% \text {; } \\
\text { - кривая большого } \\
\text { радиуса }\end{array}$ & $\begin{array}{l}\text { - от } 0.0 \text { до } 12 \% \text {; } \\
\text { - кривая малого радиуса }\end{array}$ \\
\hline $\begin{array}{l}\text { 2. Условия } \\
\text { деятельности }\end{array}$ & $\begin{array}{l}\text { Порывистый } \\
\text { ветер до } 12 \text { м/с на } \\
\text { участке } \\
\text { протяженностью } \\
300 \text { м }\end{array}$ & $\begin{array}{l}\text { Плановые } \\
\text { ремонтные работы } \\
\text { на конкретном } \\
\text { участке пути протя- } \\
\text { женностью } 300 \text { м }\end{array}$ & $\begin{array}{l}\text { Неожиданное } \\
\text { постепенное прибывание } \\
\text { сточных вод и погружение } \\
\text { рельс под воду на участке } \\
\text { протяженностью } 300 \text { м }\end{array}$ \\
\hline $\begin{array}{l}\text { 3. Способ } \\
\text { действия }\end{array}$ & $\begin{array}{l}\text { Нормативный } \\
\text { способ действия }\end{array}$ & $\begin{array}{l}\text { Комбинирование } \\
\text { нормативных } \\
\text { способов действия }\end{array}$ & $\begin{array}{l}\text { Переструктурирование } \\
\text { нормативных способов } \\
\text { действия }\end{array}$ \\
\hline $\begin{array}{l}\text { 4. Тип ситуации } \\
\text { неисправности }\end{array}$ & $\begin{array}{l}\text { При ведении } \\
\text { электропоезда за- } \\
\text { горается сиг- } \\
\text { нальная лампа ЗБ } \\
\text { (зарядка батарей), } \\
\text { нет зарядки } \\
\text { аккумуляторных } \\
\text { батарей }\end{array}$ & $\begin{array}{l}\text { При ведении } \\
\text { электропоезда } \\
\text { прекратилась работа } \\
\text { вспомогательных } \\
\text { машин }\end{array}$ & $\begin{array}{l}\text { При ведении } \\
\text { электропоезда происходит } \\
\text { отключение главного } \\
\text { выключателя в обеих } \\
\text { секциях }\end{array}$ \\
\hline
\end{tabular}

Примечание. Ситуации неисправности под влиянием высокой степени свободы в деятельности подбирались на основе малой вероятности характерных причин неисправности и редкости их встречаемости в работе машиниста.

$p \leqslant 0.01=3$ балла, для $p \leqslant 0.05=2$ балла, для $p \leqslant 0.1=1$ балл. Количество баллов суммируется. Полученная сумма отражает величину индекса когерентности системы одаренности. Чем выше индекс когерентности системы, тем более интегрированной и целостной является система одаренности (Шадриков, 2013, с. 403).

Рассмотрим результаты продуктивности деятельности в условиях различной степени свободы в группах с низкой и высокой мотивацией успеха.

Из приведенных в таблице 3 данных следует, что успешность деятельности по преимущественному числу показателей продуктивности отчетливо различается между тремя группами с низкой мотивацией успеха, выполняющих деятельность в условиях различной степени свободы.

Получены статистически значимые различия между тремя группами с низкой мотивацией успеха по показателям «продолжительность поездки», «время устранения ситуации неисправности», «уровень управления автотормоза- 
Таблица 3

Различия по показателям продуктивности деятельности под влиянием низкой, средней и высокой степени свободы на компьютерном тренажере в группах с низкой мотивацией успеха (критерий Крускала-Уоллеса)

\begin{tabular}{|c|c|c|c|c|c|c|c|c|}
\hline \multicolumn{2}{|c|}{$\begin{array}{c}\text { Степень свободы в деятельности / } \\
\text { группы }\end{array}$} & \multirow{2}{*}{\multicolumn{2}{|c|}{$\begin{array}{c}\begin{array}{c}\text { Низкая } \\
\text { степень } \\
\text { свободы в } \\
\text { деятельности }\end{array} \\
\begin{array}{c}\text { Первая группа } \\
\text { с НИЗ МОТ, } \\
\text { n = }\end{array}\end{array}$}} & \multirow{2}{*}{\multicolumn{2}{|c|}{$\begin{array}{c}\begin{array}{c}\text { Средняя } \\
\text { степень } \\
\text { свободы в } \\
\text { деятельности }\end{array} \\
\text { Вторая группа } \\
\text { с НИЗ МОТ, } \\
\text { n }=9\end{array}$}} & \multirow{2}{*}{\multicolumn{2}{|c|}{$\begin{array}{c}\begin{array}{c}\text { Высокая } \\
\text { степень } \\
\text { свободы в } \\
\text { деятельности }\end{array} \\
\begin{array}{c}\text { Третья группа } \\
\text { с НИЗ МОТ, } \\
\text { n }=9\end{array}\end{array}$}} & \multirow{3}{*}{$\begin{array}{c}\mathbf{H}_{\text {ма }} \\
\text { Крускала- } \\
\text { Уоллеса }\end{array}$} \\
\hline \multirow{2}{*}{\multicolumn{2}{|c|}{$\begin{array}{c}\text { Показатели продуктивности } \\
\text { деятельности на компьютерном } \\
\text { тренажере }\end{array}$}} & & & & & & & \\
\hline & & $X_{c p}$ & $\sum$ & $X_{c p}$ & $\sigma$ & $X_{c p}$ & $\sigma$ & \\
\hline $\begin{array}{l}\text { Производи- } \\
\text { тельность }\end{array}$ & $\begin{array}{l}\text { 1. Продолжительность } \\
\text { поездки, сек }\end{array}$ & 2720 & 626.3 & 6119 & 1602.9 & 6331.3 & 1111.8 & 15.766 \\
\hline \multirow{2}{*}{ Надежность } & $\begin{array}{l}\text { 2. Время устранения } \\
\text { ситуации } \\
\text { неисправности, сек }\end{array}$ & 317.4 & 160.1 & 581.1 & 173.4 & 720.4 & 232.4 & 12.592 \\
\hline & $\begin{array}{l}\text { 3. Количество нару- } \\
\text { шений безопасности } \\
\text { движения поезда }\end{array}$ & 2.2 & 1.9 & 4.6 & 2.8 & 4.5 & 3.04 & 4.308 \\
\hline Качество & $\begin{array}{l}\text { 4. Уровень управления } \\
\text { aвтотормозами }\end{array}$ & 2.7 & 0.4 & 1.8 & 0.7 & 2.5 & 0.5 & 7.245 \\
\hline
\end{tabular}

Примечание. НИЗ МОТ - низкая мотивация успеха. Уровень управления автотормозами: 3 - высокий, 2 - средний, 1 - низкий. Полужирным шрифтом выделены эмпирические значения $\mathrm{H}_{\text {эм }}$ Крускала-Уоллеса, попавшие в зону значимости. Критерий Крускала-Уоллеса: $\mathrm{H}_{\text {кр }}=$ $=5.991$ для $p \leqslant 0.05 ; \mathrm{H}_{\text {кр }}=9.210$ для $p \leqslant 0.01$ при $v=2$.

ми» в пользу первой группы, осуществляющей деятельность в условиях низкой степени свободы (таблица 3). Однако самый низкий уровень управления автотормозами оказался в условиях средней степени свободы в деятельности. Кроме того, в условиях низкой и высокой степени свободы в деятельности уровень управления автотормозами практически идентичен.

Таким образом, чем выше степень свободы в деятельности, тем ниже производительность и надежность, а качество деятельности снижается от низкой к средней степени свободы и повышается от средней к высокой степени свободы в деятельности.

Получены статистически значимые различия между тремя группами с высокой мотивацией успеха по показателям «продолжительность поездки», «время устранения ситуации неисправности», «количество нарушений безопасности движения поезда» в пользу первой группы, осуществляющей деятельность в условиях низкой степени свободы. Однако минимальное количество нарушений безопасности имеется в группе, выполняющей деятельность в условиях средней степени свободы (таблица 4). 
Таким образом, чем выше степень свободы в деятельности, тем ниже производительность и надежность деятельности в группах с высокой мотивацией успеха. Качество деятельности остается стабильно выполняемым субъектом вне зависимости от степени свободы в деятельности.

Рассмотрим полученные корреляционные структуры одаренности в условиях различной степени свободы в группах с низкой и высокой мотивацией успеха.

Сопоставление структур одаренности, изображенных на рисунке 1, позволяет отметить, что под влиянием низкой, средней и высокой степени свободы в деятельности имеется различный состав способностей в структурах и характер корреляционных связей между ними в группах с низкой и высокой мотивацией успеха.

В группе с высокой мотивацией успеха в условиях низкой степени свободы в деятельности структура одаренности вообе не сформировалась.

В целом в группах с низкой и высокой мотивацией успеха можно отметить, что увеличивается компонентный состав в структуре, идет нарастание корре-

Таблица 4

Различия по показателям продуктивности деятельности под влиянием низкой, средней и высокой степени свободы на компьютерном тренажере в группах с высокой мотивацией успеха (критерий Крускала-Уоллеса)

\begin{tabular}{|c|c|c|c|c|c|c|c|c|}
\hline \multicolumn{2}{|c|}{$\begin{array}{c}\text { Степень свободы в деятельности / } \\
\text { группы }\end{array}$} & \multicolumn{2}{|c|}{$\begin{array}{c}\text { Низкая } \\
\text { степень } \\
\text { свободы в } \\
\text { деятельности }\end{array}$} & \multicolumn{2}{|c|}{$\begin{array}{c}\text { Средняя } \\
\text { степень } \\
\text { свободы в } \\
\text { деятельности }\end{array}$} & \multicolumn{2}{|c|}{$\begin{array}{c}\text { Высокая } \\
\text { степень } \\
\text { свободы в } \\
\text { деятельности }\end{array}$} & \multirow{3}{*}{$\begin{array}{r}\mathbf{H}_{\text {эм }} \\
\text { Крускала- } \\
\text { Уоллеса }\end{array}$} \\
\hline \multirow{2}{*}{\multicolumn{2}{|c|}{$\begin{array}{c}\text { Показатели продуктивности } \\
\text { деятельности на компьютерном } \\
\text { тренажере }\end{array}$}} & \multicolumn{2}{|c|}{$\begin{array}{c}\text { Первая группа } \\
\text { с ВЫС МОТ, } \\
\text { n }=9\end{array}$} & \multicolumn{2}{|c|}{$\begin{array}{c}\text { Вторая группа } \\
\text { с ВЫС MOT, } \\
\text { n }=9\end{array}$} & \multicolumn{2}{|c|}{$\begin{array}{c}\text { Третья группа } \\
\text { с ВЫС MOT, } \\
\text { n }=9\end{array}$} & \\
\hline & & $X_{c p}$ & $\sum$ & $X_{c p}$ & $\sigma$ & $X_{c p}$ & $\sigma$ & \\
\hline $\begin{array}{l}\text { Производи- } \\
\text { тельность }\end{array}$ & $\begin{array}{l}\text { 1. Продолжительность } \\
\text { поездки, сек }\end{array}$ & 2843 & 472.2 & $\begin{array}{l}4653 . \\
6\end{array}$ & 1178.1 & 6142.4 & 1003.4 & 17.278 \\
\hline \multirow{2}{*}{ Надежность } & $\begin{array}{l}\text { 2. Время устранения } \\
\text { ситуации } \\
\text { неисправности, сек }\end{array}$ & 403.2 & 147.8 & 560.1 & 187.7 & 711.8 & 136.8 & 10.385 \\
\hline & $\begin{array}{l}\text { 3. Количество нару- } \\
\text { шений безопасности } \\
\text { движения поезда }\end{array}$ & 3 & 1.6 & 1.4 & 1.6 & 4.7 & 2.3 & 9.328 \\
\hline Качество & $\begin{array}{l}\text { 4. Уровень управления } \\
\text { автотормозами }\end{array}$ & 2.2 & 0.6 & 2.6 & 0.5 & 2.6 & 0.7 & 3.422 \\
\hline
\end{tabular}

Примечание. ВЫС МОТ - высокая мотивация успеха. Уровень управления автотормозами: 3 - высокий, 2 - средний, 1 - низкий. Полужирным шрифтом выделены эмпирические значения $\mathrm{H}_{\text {эм }}$ Крускала-Уоллеса, попавшие в зону значимости. Критерий Крускала-Уоллеса: $\mathrm{H}_{\text {кр }}=$ $=5.991$ для $p \leqslant 0.05 ; \mathrm{H}_{\text {кр }}=9.210$ для $p \leqslant 0.01$ при $v=2$. 
Рисунок 1

Структура одаренности в условиях низкой, средней и высокой степени свободы в деятельности групп с низкой и высокой мотивацией успеха

$$
\begin{array}{cc}
\text { Структура одаренности } & \text { Структура одаренности } \\
\text { групп с низкой } & \text { групп с высокой } \\
\text { мотивацией успеха } & \text { мотивацией успеха }
\end{array}
$$

Низкая степень свободы в деятельности
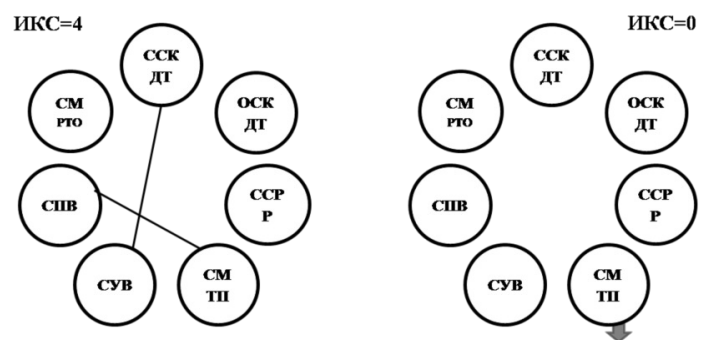

Средняя степень свободы в деятельности
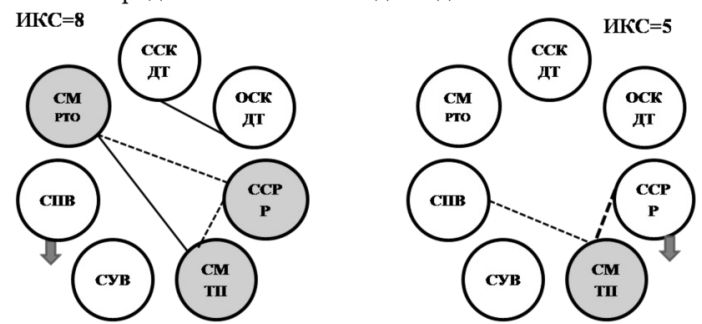

Высокая степень свободы в деятельности
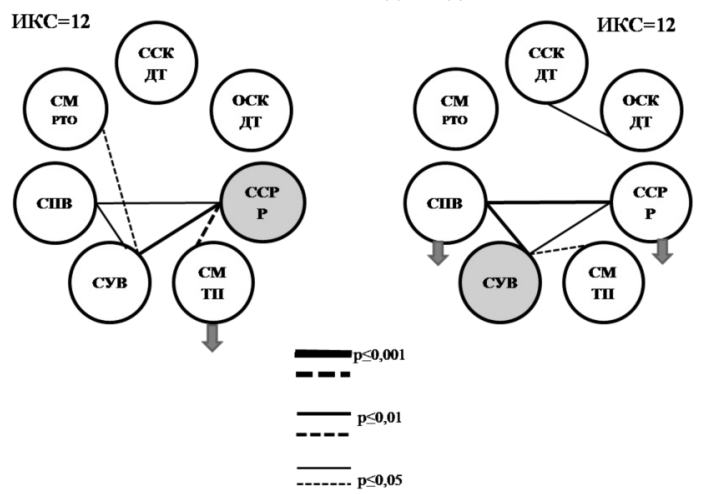

Примечание. ИКС - индекс когерентности системы. ОСКДТ - общие способности координации движений тела, ССКДТ - специальные способности координации движений тела, ССРР - способности сенсомоторной реакции рук и глаз, СПВ - способности переключения внимания, СУВ - способности устойчивости внимания, СМТП - способности мышления на уровне технического понимания, СМРТО - способности мышления на уровне реконструкции технических образов. Затемненные кружки указывают на базовые способности в структуре одаренности. Широкие стрелки от способностей указывают на то, что они являются ведущими в системе одаренности. 
ляционных связей в структуре одаренности от низкой к средней и высокой степени свободы в деятельности (рисунок 1).

Структура связей в одаренности с точки зрения ее представленности в отношении условий низкой, средней и высокой степени свободы имеет следующие характерные особенности: 1) имеются индивидуальные положительные связи в структурах; 2) имеются индивидуальные отрицательные связи в структурах; 3) имеются сходные положительные связи, но различной меры тесноты; 4) имеются сходные отрицательные связи, но различной меры тесноты (рисунок 1).

Примечательно, что во всех структурах одаренности вовлечены способности, относимые к группам сенсомоторных, аттенционных и мыслительных способностей.

Самыми структурированными и целостными системами одаренности являются системы в зависимости от низкой $(И К С=12)$ и высокой мотивации успеха (ИКС=12), сформированные в условиях высокой степени свободы в деятельности. Данные системы одаренности обеспечивают процесс разработки нового способа действия. Примечательным для данных систем одаренности является одинаковая мера интеграции, но различный состав и характер корреляционных связей (рисунок 1).

В качестве базовых выступают различные способности в системах одаренности. Однако под влиянием низкой степени свободы в системах одаренности не проявилось базовых способностей в группах с низкой и высокой мотивацией успеха (рисунок 1).

Базовыми являются такие способности, которые имеют наибольшее число значимых корреляционных связей с другими компонентами системы одаренности. Базовые способности играют интегрирующую роль в системе одаренности и являются основой для установления компенсаторных функциональных связей между ее компонентами (Шадриков, 2013).

В условиях средней степени свободы в деятельности к базовым относятся следующие способности:

- сенсомоторной реакции рук и глаз, мышления на уровне технического понимания и на уровне реконструкции технического образа в группе с низкой мотивацией успеха;

- мышления на уровне технического понимания в группе с высокой мотивацией успеха.

В условиях высокой степени свободы в деятельности к базовым относятся следующие способности:

- сенсомоторной реакции рук и глаз в группе с низкой мотивацией успеха;

- устойчивости внимания в группе с высокой мотивацией успеха (рисунок 1).

Выявлены различные ведущие способности, которые имеют наибольшее количество значимых корреляционных связей с показателями продуктивности деятельности. Ведущие способности непосредственно оказывают влияние на продуктивность деятельности (Там же). Однако в группе с низкой мотивацией успеха в структуре одаренности вообще не проявилось ведущих способностей в условиях низкой степени свободы в деятельности. 
В условиях низкой степени свободы в деятельности к ведущим относится способность:

- мышления на уровне технического понимания в группе с высокой мотивацией успеха.

В условиях средней степени свободы в деятельности к ведущим относятся следующие способности:

- переключения внимания в группе с низкой мотивацией успеха;

- сенсомоторной реакции рук и глаз в группе с высокой мотивацией успеха.

В условиях высокой степени свободы в деятельности к ведущим относятся следующие способности:

- мышления на уровне технического понимания в группе с низкой мотивацией успеха;

- сенсомоторной реакции рук и глаз, переключения внимания в группе с высокой мотивацией успеха.

\section{Обсуждение}

Полученные результаты показывают, что низкая, средняя и высокая степени свободы в деятельности обуславливают конкретные способы действия. Низкая, средняя и высокая степени свободы в деятельности проявляются в различной мере производительности, надежности и качества деятельности.

В зависимости от низкой мотивации успеха производительность, надежность и качество деятельности снижаются с повышением степени свободы в деятельности. В зависимости от высокой мотивации успеха производительность и надежность снижаются, а качество деятельности остается неизменным с повышением степени свободы в деятельности (см. таблицы 3 и 4).

Профессиональная одаренность, рассматриваемая на уровне отдельных функциональных систем, реализующих соответствующие сенсомоторные, аттенционные и мыслительные способности, представляет собой целостное структурное образование. Соответственно, в условиях низкой, средней и высокой степени свободы в деятельности одаренность может быть рассмотрена как самостоятельная система, свойства которой не сводятся к набору свойств входящих в нее компонентов, во многом они обусловлены спецификой установившихся между данными компонентами взаимосвязей и структурных отношений.

В зависимости от низкой и высокой мотивации успеха формируются различные по составу и мере интеграции структуры одаренности в условиях низкой, средней и высокой степени свободы в деятельности. Высокими функциональными возможностями обладает система одаренности, сформированная в условиях высокой степени свободы в деятельности, причем как в зависимости от низкой, так и от высокой мотивации успеха. В этой связи отметим, что, скорее всего, бо́льшую роль в интеграции системы одаренности играет высокая степень свободы в деятельности, чем низкая и высокая мотивация успеха (см. рисунок 1). 
Между тем имеется исключение: в зависимости от высокой мотивации успеха структура одаренности вообще не сформировалась под влиянием низкой степени свободы в деятельности (см. рисунок 1). В данном случае возможно, что высокая мотивация успеха, присущая субъектам, компенсирует функционирование системы одаренности и тем самым обеспечивает реализацию нормативного способа действия. Результаты исследования трудовой деятельности не противоречат данному предположению. Достижения в профессиональной деятельности являются производными от функции мотивационных влияний и способностей человека, а отправной точкой выступает свобода выбора решения субъектом (Poulton, 1970; Rockwell, 1972). В работах Е.П. Ильина, X. Хекхаузена отмечается, что сила мотивации субъекта в успешном решении трудовых задач может преодолеть недостатки в знаниях и способностях (Ильин, 2004; Хекхаузен, 2003).

Формирование структур одаренности в детерминации различными внешними и внутренними условиями подчиняется системогенетическим закономерностям неравномерности и достаточности. Взаимодействие между способностями в системах одаренности в детерминации различными внешними и внутренними условиями носит линейный и нелинейный характер. Нелинейная зависимость между способностями обусловлена оптимальным уровнем их проявления в структуре, который оказывается различным и достаточным для обеспечения низкой, средней и высокой степени свободы в деятельности. Исключение составляет структура одаренности, сформированная в зависимости от низкой мотивации успеха под влиянием низкой степени свободы в деятельности, где имеются положительные линейные связи и низкая мера интеграции (см. рисунок 1).

Формирование структур одаренности в детерминации низкой и высокой мотивацией успеха происходит как процесс смены различных базовых и ведущих способностей в условиях различной степени свободы в деятельности. Исключение составляет структура одаренности в зависимости от низкой мотивации успеха, в которой базовых и ведущих способностей не проявилось под влиянием низкой степени свободы в деятельности (см. рисунок 1).

\section{Выводы}

Проведенное экспериментальной исследование позволило нам проработать теоретическое положение С.Л. Рубинштейна и получить подтверждение того, что свобода в профессиональной деятельности детерминирована объективными требованиями деятельности, которые реализуются через различные внутренние условия, в качестве которых выступают низкая и высокая мотивация успеха и одаренность как системное взаимодействие способностей субъекта.

Формирование системы одаренности происходит как процесс взаимодействия входящих в нее познавательных и психомоторных способностей и установления связей между ними в соответствии с низкой, средней или высокой степенью свободы в деятельности, обусловленной требованиями. Реализация 
субъектом различной степени свободы в деятельности приводит к изменению целостной системы одаренности, что проявляется в индивидуальной мере продуктивности деятельности.

Одаренность в детерминации различными внешними и внутренними условиями обеспечивает как нормативный способ действия, так и его существенное переструктурирование, поэтому правомерно применять понятие одаренности в отношении как нормативного результата, так и выдающегося, творческого результата деятельности.

\section{Литература}

Абульханова, К. А. (1999). Психология и сознание личности (Проблемы методологии, теории и исследования реальной личности): Избранные психологические труды. М./Воронеж: Московский психолого-социальный институт/НПО «МОДЭК», 1999.

Бабаева, Ю. Д. (1997). Динамическая теория одаренности. В кн. Д. Б. Богоявленская (ред.), Основные современные концепции творчества и одаренности (с. 275-294). М.: Молодая гвардия.

Богоявленская, Д. Б. (2009). Психология творческих способностей: Монография. Самара: Издательский дом «Федоров».

Богоявленская, Д. Б., Шадриков, В. Д. (ред.). (1998). Рабочая конщепщия одаренности. М.: Магистр.

Воронин, А. Н. (2011). Психология способностей в условиях глобализации. В кн. В. А. Бодров, А. Л. Журавлев (ред.), Актуальные проблемы психологии труда, инженерной психологии и эргономики (вып. 2, с. 243-267). М.: Институт психологии РАН.

Голубева, Э. А. (2005). Способности. Личность. Индивидуальность. Дубна: Феникс, 2005.

Дружинин, В. Н. (2008). Психология общих способностей. СПб.: Питер.

Ильин, Е. П. (2004). Психология индивидуальных различий. СПб.: Питер.

Карпов, А. В. (2004). Метасистемная организация уровневых структур психики. М.: Институт психологии РАН.

Матюшкин, А. М. (2003). Мьиление, обучение, творчество. М./Воронеж: Московский психолого-социальный институт/НПО «МОДЭК».

Мелик-Пашаев, А. А. (1981). Педагогика искусства и творческие способности. М.: Знание.

Панов, В. И. (2005). Одаренность и одаренные дети: Экопсихологический подход: Монография. М.: РУДН.

Панов, В. И. (2011). Одаренность и профессиональные способности. В кн. В. А. Бодров, А. Л. Журавлев (ред.), Актуальные проблемь психологии труда, инженерной психологии и эргономики (вып. 2, с. 224-242). М.: Институт психологии РАН.

Платонов, К. К. (1972). Проблемы способностей. М.: Наука.

Рубинштейн, С. Л. (1973). Человек и мир. Проблемы общей психологии. М.: Педагогика.

Теплов, Б. М. (1985). Избранные труды: T. 1. Способности и одаренность. М.: Педагогика.

Толочек, В. А. (2011). Профессиональные способности, потенциал и успешность субъекта: критический анализ проблемы и модели исследования. В кн. В. А. Бодров, А. Л. Журавлев (ред.), Актуальные проблемы психологии труда, инженерной психологии и әргономики (вып. 2, с. 320-343). М.: Институт психологии РАН. 
Ушаков, Д. В. (2011). Психология интеллекта и одаренности. М.: Институт психологии РАН. Хекхаузен, Х. (2003). Мотивация и деятельность. СПб./М.: Питер/Смысл.

Холодная, М. А. (2002). Психология интеллекта. Парадоксы исследования. СПб.: Питер.

Шадриков, В. Д. (2013). Психология деятельности человека. М.: Институт психологии РАН.

Шадриков, В. Д. (2019). Способности и одаренность человека. М.: Институт психологии РАН.

Ссылки на зарубежные источники см. в разделе References после англоязычного блока.

Соболева Татьяна Николаевна - доцент, кафедра общей, юридической и инженерной психологии, Дальневосточный государственный университет путей сообщения, кандидат психологических наук, доцент.

Сфера научных интересов: профессиональные способности, одаренность.

Контакты: t.n.s.25vivat@mail.ru 


\title{
The Formation of Professional Talent and Its Determination by the Low and High Motivation for Success under the Influence of Different Degrees of Freedom in Activity
}

\author{
T.N. Soboleva ${ }^{a}$ \\ ${ }^{a}$ The Far Eastern State Transport University, 47, Seryshev Str., Khabarovsk, 680021, Russian Federation
}

\begin{abstract}
This article is devoted to the poorly studied problem of the formation of professional talent in the conditions of different degrees of freedom in activity and the influence of a person's low or high motivation for success on this formation. Three degrees of freedom in activity have been identified and described: the low degree of freedom is due to the normative mode of action; the average degree of freedom is due to the combined mode of action from the subject's experience and regulatory instructions; and the high degree of freedom is due to the creation of a new mode of action. The main objective of the study is to describe how the conditions of different degrees of freedom in activity are refracted with internal conditions, which are low and high motivation for success, and various talent structures. The study was conducted on a sample of 54 qualified train drivers using a specialized simulator, which allows simulating three degrees of freedom in activity. The psychological analysis of activity revealed seven abilities ensuring the implementation of activity. Based on the empirical data, it is shown that low, medium, and high degrees of freedom in activity are manifested in different measures of productivity. Low and high motivation for a person's success in freedom of choice conditions in the activity does not influence the productivity of the activity. Along with this, depending on the low and high motivation for success, different structures of talent in terms of composition and degree of integration under the conditions of different degrees of freedom in the activity are formed. On the one hand, the low and high motivation for success acts as internal determinants, on the other hand, low, medium and high degrees of freedom in the activity act as external determinants for the formation of various talent structures.
\end{abstract}

Keywords: freedom in professional activity, normative mode of action, motivation for success, talent structure.

\section{References}

Abul'khanova, K. A. (1999). Psikhologiya i soznanie lichnosti (Problemy metodologii, teorii $i$ issledovaniya real'noi lichnosti): Izbrannye psikhologicheskie trudy [Psychology and consciousness of personality (Problems of methodology, theory and study of real personality): Selected psychological works]. Moscow/Voronezh: Moskovskii psikhologo-sotsial'nyi institut/NPO "MODEK". (in Russian)

Babaeva, Yu. D. (1997). Dinamicheskaya teoriya odarennosti [The dynamic theory of talent]. In D. B. Bogoyavlenskaya (Ed.), Osnovnye sovremennye kontseptsii tvorchestva i odarennosti [Basic modern concepts of creativity and talent] (pp. 275-294). Moscow: Molodaya gvardiya. (in Russian) 
Bogoyavlenskaya, D. B. (2009). Psikhologiya tvorcheskikh sposobnostei [The psychology of creativity]. Samara: Izdatel'skii dom "Fedorov". (in Russian)

Bogoyavlenskaya, D. B., \& Shadrikov, V. D. (Eds.). (1998). Rabochaya kontseptsiya odarennosti [The working concept of talent]. Moscow: Magistr. (in Russian)

Druzhinin, V. N. (2008). Psikhologiya obshchikh sposobnostei [The psychology of general abilities]. Saint Petersburg: Piter. (in Russian)

Golubeva, E. A. (2005). Sposobnosti. Lichnost'. Individual'nost' [Abilities. Personality. Individuality]. Dubna: Feniks. (in Russian)

Heckhausen, H. (2003). Motivatsiya i deyatel'nost' [Motivation and activity]. Saint Petersburg/ Moscow: Piter/Smysl. (in Russian; transl. of: Heckhausen, H. (1980). Motivation und Handeln. Lehrbuch der Motivationspsychologie. Berlin: Springer. (in Deutsch))

Il'in, E. P. (2004). Psikhologiya individual'nykh razlichii [The psychology of individual differences]. Saint Petersburg: Piter. (in Russian)

Karpov, A. V. (2004). Metasistemnaya organizatsiya urovnevykh struktur psikhiki [Metasystem organization of level structures of the mind]. Moscow: Institute of Psychology of the RAS. (in Russian)

Kholodnaya, M. A. (2002). Psikhologiya intellekta. Paradoksy issledovaniya [The psychology of intelligence. Research paradoxes]. Saint Petersburg: Piter. (in Russian)

Matyushkin, A. M. (2003). Myshlenie, obuchenie, tvorchestvo [Thinking, learning, creativity]. Moscow/Voronezh: Moskovskii psikhologo-sotsial'nyi institut/NPO "MODEK". (in Russian)

Melik-Pashaev, A. A. (1981). Pedagogika iskusstva i tvorcheskie sposobnosti [Pedagogy of art and creative abilities]. Moscow: Znanie. (in Russian)

Panov, V. I. (2005). Odarennost' i odarennye deti: Ekopsikhologicheskii podkhod [Giftedness and gifted children: Ecopsychological approach]. Moscow: RUDN University. (in Russian)

Panov, V. I. (2011). Odarennost' i professional'nye sposobnosti [Talent and professional abilities]. In V. A. Bodrov \& A. L. Zhuravlev (Eds.), Aktual'nye problemy psikhologii truda, inzhenernoi psikhologii i ergonomiki [Topical issues of labor psychology, engineering psychology and ergonomics] (Iss. 2, pp. 224-242). Moscow: Institute of Psychology of the RAS. (in Russian)

Platonov, K. K. (1972). Problemy sposobnostei [Ability problems]. Moscow: Nauka. (in Russian)

Poulton, E. C. (1970). Environment and human efficiency. Springfield, IL: Charles C. Thomas.

Rockwell, T. (1972). Skills, judgment and information acquisition in driving. In T. W. Forbes (Ed.), Human factors in highway traffic safety research (pp. 133-164). New York: Wiley.

Rubinstein, S. L. (1973). Chelovek i mir. Problemy obshchei psikhologii [A person and the world. Issues of general psychology]. Moscow: Pedagogika. (in Russian)

Shadrikov, V. D. (2013). Psikhologiya deyatel'nosti cheloveka [The psychology of human activity]. Moscow: Institute of Psychology of the RAS. (in Russian)

Shadrikov, V. D. (2019). Sposobnosti i odarennost' cheloveka [Human abilities and talent]. Moscow: Institute of Psychology of the RAS. (in Russian)

Teplov, B. M. (1985). Izbrannye trudy [Selected works]: Vol. 1. Sposobnosti i odarennost' [Abilities and talent]. Moscow: Pedagogika. (in Russian)

Tolochek, V. A. (2011). Professional'nye sposobnosti, potentsial i uspeshnost' sub"ekta: kriticheskii analiz problemy i modeli issledovaniya [Professional abilities, potential and success of the subject: a critical analysis of the problem and the research model]. In V. A. Bodrov \& A. L. Zhuravlev (Eds.), Aktual'nye problemy psikhologii truda, inzhenernoi psikhologii i ergonomiki [Topical issues of labor psychology, engineering psychology and ergonomics] (Iss. 2. pp. 320-343). Moscow: Institute of Psychology of the RAS. (in Russian) 
Ushakov, D. V. (2011). Psikhologiya intellekta i odarennosti [The psychology of intelligence and talent]. Moscow: Institute of Psychology of the RAS. (in Russian)

Voronin, A. N. (2011). Psikhologiya sposobnostei v usloviyakh globalizatsii [Psychology of abilities in the context of globalization]. In V. A. Bodrov \& A. L. Zhuravlev (Eds.), Aktual'nye problemy psikhologii truda, inzhenernoi psikhologii i ergonomiki [Topical issues of labor psychology, engineering psychology and ergonomics] (Iss. 2, pp. 243-267). Moscow: Institute of Psychology of the RAS. (in Russian)

Soboleva Tatyana Nikolaevna - Associate Professor, General, Legal and Engineering Psychology Department, The Far Eastern State Transport University, PhD in Psychology, Associate Professor.

Research Area: professional abilities, talent.

Email: t.n.s.25vivat@mail.ru 